\title{
Product Market Competition, Incentives and Fraudulent
}

\author{
Behavior* \\ Rainer Andergassen \\ Department of Economics, University of Bologna, Italy \\ CIG, Centro Interdipartimentale Luigi Galvani \\ RCEA, Rimini Centre for Economic Analysis, Italy \\ E-mail: rainer.andergassen@unibo.it
}

March, 2009

Abstract. The present paper studies incentive provision in a model where a manager can affect the firm's stock price by exerting unobservable effort and through costly, deceptive signalling and investigates the role product market competition plays in shaping shareholders' trade-off between inducing effort and fraud.

KEYWORDS: executive compensation, fraud, incentives, product market competition

JEL: D82, G30, J33, L1

*The author would like to thank Vincenzo Denicolò for helpful comments. The usual disclaimer applies. 


\section{Introduction}

The enormous increase in stock and stock-option based compensation experienced during the 1990s in the USA (Murphy, 1999) has initially been welcomed as a way to align managers' and shareholders' interests and to reduce agency costs (see Jensen and Meckling, 1976). Accounting scandals during the 1990s and early 2000s have brought compensation practices for CEOs under close scrutiny and stock based compensation has since been viewed as a double edged sword (Goldman and Slezak, 2006).

In this paper we study incentive provision in a model where the manager can affect the firm's stock price by exerting unobservable effort and through costly, deceptive signalling. In this context, shareholders face a trade-off between effort and fraud and they may find eliminating fraudulent behavior too costly since it may curb effort. We investigate how product market competition (PMC) affects this trade-off. Common wisdom holds that competition has a positive influence on managerial behavior. While recent literature investigates the link between PMC and managerial effort (see, for example, Raith, 2003 and Vives, 2008), this literature neglects the possibility that incentives may also stimulate fraudulent behavior.

We consider a 2 period economy with a continuum of measure one of duopolistic sectors. Each firm is run by a manager and firm profits depend on an exogenously given firm-specific demand level, which, for simplicity, we consider to be either high or low, and which is unknown to shareholders and to the manager prior to his hiring (but private information once he got hired) and on managerial effort. The present model features both hidden action (managerial effort) and hidden information (exogenous demand shock). A manager, by exerting effort, is able to "steal" market share from others. On the other hand, he may also manipulate the company's short term stock price signalling an inflated demand level to the market, but decreasing in this way the firm's long term profits ${ }^{1}$. We assume that the manager pockets his compensation at the end of time

\footnotetext{
1 Several paper document the negative relationship between earnings manipulation and its negative effects on the future stock price. Chan et al (2006) using accounting accruals as a proxy for the quality of reported earnings
} 
1 (that is, managers have a short time horizon) while the shareholders are paid dividends at the end of time period 2 (that is, shareholders have a long time horizon). Thus, the manager may try to manipulate the company's short term share price in order to boost his compensation at the expense of the company's long term performance.

We study incentives, in terms of stock-based compensation, and fraudulent behavior as the degree of competition varies. We model PMC inversely by the degree to which firms in a sector are able to collude (see Aghion et al., 2005).

In providing incentives, shareholders face a trade-off between fraud and effort. Given that fraudulent managers face a constant expected penalty, we show that sufficiently weak incentives eliminate fraudulent behavior. Thus, shareholders are always able to enforce a separating equilibrium where managers truthfully signal the company's demand level. From the shareholders' viewpoint, enforcing a separating equilibrium may be too costly, since it may provide the manager with too few incentives to exert effort. In this case, a pooling equilibrium may be optimal where all managers signal a high demand level, and hence where shareholders allow for some fraudulent behavior.

We find that the pay-for-performance sensitivity is non-monotone in the strength of PMC while the equilibrium level of fraudulent behavior decreases as the rent reduction effect increases. This leads to a non-monotone relationship between incentives and fraudulent behavior as PMC varies. Consequently, it may happen that strong incentives do not lead to fraudulent behavior if these are associated with a sufficiently strong PMC while the same or weaker incentives lead to fraudulent behavior if PMC is sufficiently weak. Moreover, the non-monotone relationship between PMC and incentives implies that stronger PMC may lead to stronger incentives.

find a strong evidence of earnings manipulations in firms with the largest accruals and that accruals are negatively related to future stock market returns. Teoh, Welch and Wong (1998a) show how issuers of initial public offerings (IPOs) with unusually high accrual in the year of issue experience poor stock performance in the subsequent three years. Teoh, Welch and Wong (1998b) provide evidence that pre-issue earnings management by seasoned equity issuers, as reflected in discretionary accruals, explains future underperformance in stock returns. See also Jensen (2003). 
The paper contributes to the literature on PMC and managerial incentives ${ }^{2}$ and to the literature on managerial incentives and fraudulent behavior ${ }^{3}$. In models investigating the relationship between PMC and managerial incentives, incentives of shareholders translate monotonically, via the incentive scheme, into managerial incentives. We show that if fraudulent behavior is taken into account, then market driven incentives of shareholders are translated non-monotonically into managerial incentives. Moreover, we find that even in the absence of a business stealing effect, stronger PMC may lead the shareholder to provide the manager with stronger incentives. The literature on incentives and fraudulent behavior argues that the stronger are the incentives, the higher is the probability of observing fraudulent behavior, (Goldman and Slezak, 2006). We show that, once PMC is taken into account, a non-monotone relationship between incentives and fraudulent behavior exists. Stronger incentives may not lead to fraudulent behavior if PMC is sufficiently strong, while weaker incentives may lead to fraudulent behavior if PMC is weak.

The remaining part of the paper is organized as follows. In Section 2 we review the related literature. In Section 3 we outline and solve the model. Section 4 concludes.

\section{Related Literature}

Incentives as a double-edged sword are modelled in Goldman and Slezak (2006) where it is shown that the potential for information manipulation affects the equilibrium level of pay-for-performance sensitivity. The authors consider a principle/agent model with hidden action (unobservable effort) and study the "signal jamming" equilibrium whereby an agent takes a costly action that is intended to mislead but actually misleads no one in equilibrium. In their model without "naive investors" the firm value is adjusted to fully correct for the extent of the bias in the manipulated information, while "naive investors" are needed to generate fluctuations in the stock price.

Our paper is most closely aligned with Crocker and Slemrod (2007) who study a model where

\footnotetext{
2 See, for example, Raith (2003) and Vives (2008).

3 See, for example, Goldman and Slezak (2006), Bebchuk and Bar-Gill (2003), Philippon and Kedia (2007), Crocker and Slemrod (2007), Povel, Sing and Winton (2007).
} 
a manger's hidden action affects firm profits and where realized profits are hidden information known only to the manager. The authors show that compensation contracts contingent on reported earnings cannot provide managers with the incentive both to maximize profits and to report those profits honestly.

The real costs of fraudulent accounting in terms of investment and employment are studied in Philippon and Kedia (2007). The authors find that during periods of fraudulent behavior, firms invest and hire more than comparable matched firms. Povel, Sing and Winton (2007) study in a model of financing and investment equilibrium fraud and monitoring decisions. The authors show that incentives to commit fraud are highest towards the end of booms and that this link becomes stronger as monitoring costs decrease.

Several empirical studies try to relate pay-for-performance sensitivity with fraudulent behavior. Erickson, Hanlon and Maydew (2006) study a sample consisting of 50 firms accused of accounting fraud by the SEC during January 1996 to November 2003 and compare the fraud firms with a matched and unmatched sample of firms to examine whether executive equity incentives are positively associated with accounting fraud. The authors find that controlling for corporate governance, the desire for external financing, financial performance and firm size, this association becomes insignificant. Burns and Kedia (2006) comparing earning restatements of 215 firms with a control sample of firms matched by industry and size find that equity, restricted stock and LTIP do not have any significant impact on the propensity and magnitude to misreport but find strong evidence that higher incentives from stock options are associated with a higher propensity to misreport and also with a higher magnitude of misreporting. Bergstresser and Philippon (2006) consider accruals-based measures of earnings management and find that periods of high accruals coincide with unusually large options exercise of CEOs and with sale of large quantities of shares by other insiders. Gao and Shrieves (2002) investigate the relationship between earnings management intensity, as measured by the absolute value of discretionary current accruals scaled down by asset size, and managers' compensation package. They find a positive relationship between 
earnings management and stock option based compensation, while they find a weaker support for a positive association between earnings management and restricted stock. The authors find that executives at fraud firms face significantly greater financial incentives stemming from stock and options holdings. Moreover they find that during the fraud period, executives exercise also a larger fraction of vested options than executives at control firms do.

\section{The model}

We consider a two period model, where time 1 is the short term and time 2 is the long term, with a continuum of measure one of duopolistic sectors and a continuum of measure two of identical managers. Firms are run by managers. Each firm issues one share and all earnings are paid out as dividends at the final date. Demand of firm $i$ in sector $j$ is $q_{i}^{j}=\frac{1}{2} \frac{\phi_{i}^{j}}{\bar{\phi}} \frac{R}{p^{j}}$, where $\frac{\phi_{i}^{j}}{\bar{\phi}} R=$ $\theta_{i}^{j}+\frac{1}{2}\left(e_{1}^{j}+e_{2}^{j}\right)-\bar{e}$, for $i=1,2$ and $j \in[0,1]$ and $R$ is aggregate income and $p^{j}$ the price of good j. $\theta_{i}^{j}$ is an exogenous i.i.d. demand shock, which takes value $\theta^{H}$ with probability $\frac{1}{2}$ and $\theta^{L}$ with probability $\frac{1}{2}$, where $2 \theta^{L}>\theta^{H}>\theta^{L}$ and $\frac{1}{2}\left(\theta^{H}+\theta^{L}\right)=R . e_{i}^{j}$ denotes the effort of the manager of company $i$ belonging to sector $j$, for $i=1,2$ and $j \in[0,1], \bar{e}$ is the average managerial effort, where the average is taken over all firms. We assume that $\theta$ is unknown to the company and to the manager prior to his hiring. We further assume that the two firms face unit production costs $\beta^{j}$ and define $\varepsilon^{j} \equiv \frac{1}{2} \frac{p^{j}-\beta^{j}}{p^{j}}, \varepsilon^{j} \in\left(0, \frac{1}{2}\right)$. Following Aghion et al. (2005), we model the degree of product market competition inversely by the degree to which the two firms in a sector are able to collude. For $\varepsilon^{j}=0$ the two firms are unable to collude and thus Bertrand competition drives profits to zero, while the larger is $\varepsilon^{j}$, the weaker is the competition between the two firms.

Without loss of generality we assume that $\varepsilon^{j}=\varepsilon$ for each $j \in[0,1]$. True firm profits can be written as

$$
\pi_{i}^{j}=\varepsilon\left[\theta_{i}^{j}+\frac{1}{2}\left(e_{i}^{j}+e_{m}^{j}\right)-\bar{e}\right]-W\left(S_{i}^{j}\right) \quad \text { for } j \in[0,1], i \neq m=1,2
$$

where $W(S)=\omega_{0}+\omega_{1} S$ is the manager's compensation package, being a function of the company's 
stock price $S$. Given that there is a continuum of measure one of sectors in the economy we exclude the possibility that firms choose managerial incentives in a cooperative way.

\subsection{The timing}

The timing is as follows. At the beginning of time period 1 the company offers the manager a compensation package $\left(\omega_{0}, \omega_{1}\right)$. After having accepted the contract the manager learns $\theta$, chooses effort $e$ and a signal $x \in\left\{\theta^{H}, \theta^{L}\right\}$ whose cost we normalize for simplicity to $c^{j}(x)=\left|x-\theta^{j}\right|$. A truthful signal is costless $c^{j}\left(\theta^{j}\right)=0$ for $j \in\{H, L\}$, while an untruthful signal is costly $c^{i}\left(\theta^{j}\right)=\theta^{H}-\theta^{L} \equiv \Delta$, for each $j \neq i, i, j \in\{H, L\}$. In equilibrium all managers are offered the same incentive contract and therefore we assume that managers are randomly matched with firms. At the end of time 1 the executive pockets his compensation. Managers of a $L$-type company may have an incentive to pool with a $H$-type company. Pooling occurs if a manager of a $L$-type firm signals $\theta^{H}$, inflating in this way the short term stock price at the cost of a reduced long term stock price. On the contrary, in the present framework a manager of a $H$-type firm has no incentive to signal $\theta^{L}$. At time 2 products are sold and dividends are paid to shareholders.

We assume rational expectations and rational inference, that is Bayes' law, and normalize the risk free interest rate to zero. Moreover, we assume that both shareholders and managers are risk neutral and that managers are effort averse.

\subsection{Stock prices}

Given that the manager signals $x=\theta^{H}$, given $e_{1}$ and $e_{2}$ and that, in equilibrium, a fraction $\lambda \in(0,1)$ of executives managing a $L$-type company signal $\theta^{H}$ and using Bayes' law, the asset price at time 1 is

$$
S^{H} \equiv E\left(\pi \mid x=\theta^{H}, \lambda\right)=\varepsilon\left\{\frac{\lambda}{1+\lambda}\left(\theta^{L}-\Delta\right)+\frac{1}{1+\lambda} \theta^{H}+\left[\frac{1}{2}\left(e_{1}+e_{2}\right)-\bar{e}\right] \eta\right\}-\omega_{0}-\omega_{1} S^{H}
$$

which, after rearranging terms, reads as

$$
S^{H}=(1-\alpha)\left\{\varepsilon\left[\frac{\lambda}{1+\lambda}\left(\theta^{L}-\Delta\right)+\frac{1}{1+\lambda} \theta^{H}+\frac{1}{2}\left(e_{1}+e_{2}\right)-\bar{e}\right]-\omega_{0}\right\},
$$


where $\alpha=\frac{\omega_{1}}{1+\omega_{1}}$. Note that $\alpha$ is increasing in $\omega_{1}$ and therefore we consider $\alpha$ as a proxy for the pay-for-performance sensitivity. Given that a manager at time 1 signals $x=\theta^{L}$, and given $e_{1}$ and $e_{2}$, the asset price at time 1 , after rearranging terms, is

$$
S^{L} \equiv E\left(\pi \mid x=\theta^{L}\right)=\varepsilon\left\{\theta^{L}+\left[\frac{1}{2}\left(e_{1}+e_{2}\right)-\bar{e}\right] \eta\right\}-\omega_{0}-\omega_{1} S^{L}
$$

which, after rearranging terms, reads as

$$
S^{L}=(1-\alpha)\left\{\varepsilon\left[\theta^{L}+\frac{1}{2}\left(e_{1}+e_{2}\right)-\bar{e}\right]-\omega_{0}\right\}
$$

If $\lambda=0$, then no pooling occurs; for $\lambda>0$ we have that the market undervalues $H$-type companies while it overvalues some $L$-type companies.

\subsection{Fraud and effort}

The manager's utility function is

$$
U(S)=W(S)-\frac{1}{4} \frac{1}{\eta} e^{2}
$$

All managers in equilibrium are offered the same contract $\left(\omega_{0}, \omega_{1}\right)$. The expected utility of a manager of a $m$-type company signalling $\theta^{j}$ is $U_{m, j}, m=1,2, i, j=L, H$. Substituting (2) and (3) into (4) we have

$$
U_{m, H}=(1-\alpha) \omega_{0}+\alpha \varepsilon\left[\frac{\lambda}{1+\lambda}\left(\theta^{L}-\Delta\right)+\frac{1}{1+\lambda} \theta^{H}+\frac{1}{2}\left(e_{m}+e_{l}\right)-\bar{e}\right]-\frac{1}{4} \frac{1}{\eta} e_{m}^{2}
$$

and

$$
U_{m, L}=(1-\alpha) \omega_{0}+\alpha \varepsilon\left[\theta^{L}+\frac{1}{2}\left(e_{m}+e_{l}\right)-\bar{e}\right]-\frac{1}{4} \frac{1}{\eta} e_{m}^{2},
$$

with $m \neq l=1,2$. Managers choose effort maximizing expected utility. From (5) and (6), optimal effort is $e^{*}=\alpha \varepsilon \eta$ and therefore effort is larger the stronger are incentives $(\alpha)$, the weaker is PMC and the lower is the disutility of effort (i.e. the larger is $\eta$ ).

A manager caught signalling fraudulently $\theta^{H}$ suffers a punishment whose expected value we assume to be $\gamma>0$. Managers engage in fraudulent signalling as long as the expected utility of 
untruthful signalling is not lower than the expected utility of truthful signalling. Since, all other things being equal, $U_{m, H}$ is decreasing in $\lambda$, the unique equilibrium value of $\lambda$ is implicitly defined by

$$
U_{m, H}-\gamma=U_{m, L}
$$

$m=1,2$. Using (5) and (6), (7) yields the equilibrium level of fraud

$$
\lambda=\max \left\{\frac{\alpha \varepsilon \Delta-\gamma}{\alpha \varepsilon \Delta+\gamma}, 0\right\}
$$

$\lambda$, if positive, is increasing in $\alpha$ and $\varepsilon$ and decreasing in $\gamma$. Thus, the stronger is PMC and/or the larger is the expected punishment, the lower is the equilibrium level of fraud. The intuition for this is that the stronger is PMC and/or the weaker are incentives and/or the larger is the expected punishment, the lower are the expected gains from fraudulent behavior, and, as a consequence, the lower is fraudulent behavior in equilibrium. Moreover, by choosing a sufficiently low value of $\alpha$, the company is always able to induce a separating equilibrium. Enforcing a separating equilibrium may be too costly since a low $\alpha$ leads to a low effort level. $\frac{\gamma}{\varepsilon \Delta}$ is the threshold for $\alpha$ below which incentives do not lead to fraudulent behavior. Thus, below $\frac{\gamma}{\varepsilon \Delta}$, incentives and fraud are uncorrelated, while above they are positively related and therefore a trade-off between effort and fraud exists.

\subsection{The compensation contract}

At the beginning of time period 1, the shareholders' problem is to find the compensation package $\left(\omega_{0}, \omega_{1}\right)$, or equivalently $\left(\omega_{0}, \alpha\right)$, that maximizes the company's expected long term stock price. We first calculate $\omega_{0}$. Given the assumption of risk-neutrality of managers and given that in equilibrium a fraction $\lambda$ of managers of $L$-type companies engage in fraudulent behavior and that

$\frac{1}{2}$ of the companies are $L$-type and $\frac{1}{2}$ are $H$-type, the manager's expected utility before learning $\theta$ is

$$
E(U)=\frac{1}{2}\left[(1+\lambda) U_{m, H}+(1-\lambda) U_{m, L}\right]
$$


We normalize the outside option of managers to zero $\left(U_{0}=0\right)$. Using (5) and (6), where $e_{m}=$ $e^{*}=\alpha \varepsilon \eta$ and $e_{l}=\bar{e}$, the managers' participation constraint reads

$$
E(U)=(1-\alpha) \omega_{0}+\alpha \varepsilon\left[\frac{1}{2}\left(\theta^{H}+\theta^{L}\right)-\frac{1}{2} \lambda \Delta-\frac{1}{2} \bar{e}+\frac{1}{4} \alpha \varepsilon \eta\right]=0
$$

Given that in equilibrium a fraction $\lambda$ of managers of $L$-type companies engage in fraudulent behavior and that $\frac{1}{2}$ of the companies are $L$-type and $\frac{1}{2}$ are $H$-type, the expected long term stock price reads

$$
E(S)=\frac{1}{2}\left[(1+\lambda) S^{H}+(1-\lambda) S^{L}\right] .
$$

Using $S^{H}$ and $S^{L}$ defined in (2) and (3), respectively, effort $e^{*}$ for the company's manager and $\bar{e}$ for the company's sectoral rival, and $\omega_{0}$ obtained from the participation constraint (9), we can rewrite (10) as

$$
E(S)=\varepsilon\left[R-\frac{1}{2} \bar{e}+\left(1-\frac{1}{2} \alpha\right) \frac{1}{2} \alpha \varepsilon \eta-\frac{1}{2} \lambda \Delta\right],
$$

where $\lambda$ is given by (8). The first three terms of (11) represent the expected stock price in absence of fraudulent behavior; the fourth term represents agency costs because of fraudulent behavior.

Observe that the long term stock price (11) is decreasing in $\lambda$ and, moreover, using the envelope theorem, it is increasing in $\gamma$. Thus, the larger is the expected punishment $\gamma$, the lower is, in equilibrium, the fraction of firms engaging in fraud, and hence the larger is the long term stock price.

Throughout the remaining part of the paper we make use of the following assumption.

Assumption 1 Parameters $\eta, \gamma$ and $\Delta$ are such that $k \equiv 2 \frac{\eta \gamma}{\Delta^{2}}>2$.

Let us define $\alpha_{\max } \equiv \arg \max _{\alpha \in[0,1]} E(S)$ and thresholds $\varepsilon^{*} \equiv \frac{\gamma}{\Delta}$ and $\bar{\varepsilon} \equiv \frac{\gamma}{\Delta} \frac{k}{k-1}$, where Assumption 1 guarantees that $\bar{\varepsilon}>\varepsilon^{*}$.

Proposition 1 (i) For $\varepsilon>\bar{\varepsilon}, \alpha_{\max }=\widehat{\alpha}$ and $\lambda>0$, where $\frac{d \widehat{\alpha}}{d \varepsilon}>0$ and $\frac{d \widehat{\alpha}}{d \gamma}<0$; (ii) for $\varepsilon^{*} \leq \varepsilon \leq \bar{\varepsilon}$, $\alpha_{\max }=\frac{\gamma}{\Delta \varepsilon}$ and $\lambda=0$; (iii) for $\varepsilon<\varepsilon^{*}, \alpha_{\max }=1$ and $\lambda=0$. 
PMC has a twofold effect on incentive provision. The stronger (weaker) is PMC, (a) the less (more) important is effort for firm profits, and (b) the larger (lower) is the threshold below which incentives do not lead to fraudulent activity. It follows that, the stronger (weaker) is PMC, the lower (larger) is the cost of avoiding fraud in equilibrium. Therefore, if PMC is sufficiently weak then it is optimal to provide the manager with strong incentives even if this may lead to some fraudulent behavior (part (i) of Proposition 1). For intermediate values $\varepsilon$ it is optimal to set incentives to avoid fraudulent behavior (part (ii) of Proposition 1). If PMC is sufficiently strong, then fraud is avoided at zero costs since incentives do not lead to fraudulent behavior (part (iii) of Proposition $1^{4}$ ). Note that the weaker is PMC, the larger is $\widehat{\alpha}$ and $\lambda$. The weaker is PMC, the lower are marginal costs of incentives and the larger are their marginal gains and therefore the larger is the pay-for-performance sensitivity. Note also that $\varepsilon^{*}, \bar{\varepsilon}$ are increasing in $\gamma$. The larger is the expected punishment $\gamma$, the lower are the managers' incentives to engage in fraudulent behavior and thus the lower are the costs of avoiding fraud in equilibrium. Moreover, for $\alpha_{\max }>\frac{\gamma}{\varepsilon \Delta}$, the larger is $\gamma$, the larger are the marginal costs of incentives and as a consequence the lower is the pay-for-performance sensitivity.

Next we study the relationship between PMC and incentive provision $\left(\alpha_{\max }\right)$. Consider the case where initially $\varepsilon<\varepsilon^{*}$, with $\alpha_{\max }=1$ and $\lambda=0$. Since the no-fraud threshold $\frac{\gamma}{\varepsilon \Delta}$ is decreasing in $\varepsilon$, a sufficiently weak PMC will lead to some fraudulent behavior. Proposition 1, part (ii), states that for intermediate values of $\varepsilon$ it is optimal to set incentives to avoid fraudulent behavior. In this region incentives $\left(\alpha_{\max }=\frac{\gamma}{\varepsilon \Delta}\right)$ are decreasing in $\varepsilon$. For sufficiently large values of $\varepsilon$ the cost of implementing a separation equilibrium is too large and therefore $\alpha_{\max }=\widehat{\alpha}$ and $\lambda>0$, with $\widehat{\alpha}$ and $\lambda$ both increasing in $\varepsilon$ (Proposition 1, part (i)). This proves the following result.

Proposition 2 Incentives $\left(\alpha_{\max }\right)$ are non-monotone in $\varepsilon$, while $\lambda$ is increasing in $\varepsilon$.

A consequence of this result is that there exists a non-monotone relationship between incentives

\footnotetext{
${ }^{4}$ Note that $\alpha_{\max }=1$ implies that the owners sell the company to the manager at price $\omega_{0}$, where $\omega_{0}$ is obtained from the participation constraint (9).
} 
$\left(\alpha_{\max }\right)$ and fraudulent behavior $(\lambda)$ as PMC varies. Strong PMC (low $\varepsilon$ ) may lead to relatively strong incentives and no fraudulent behavior while weak PMC (large $\varepsilon$ ) may lead to relatively weak incentives and some fraudulent behavior in equilibrium. See Figure 1 for an example.

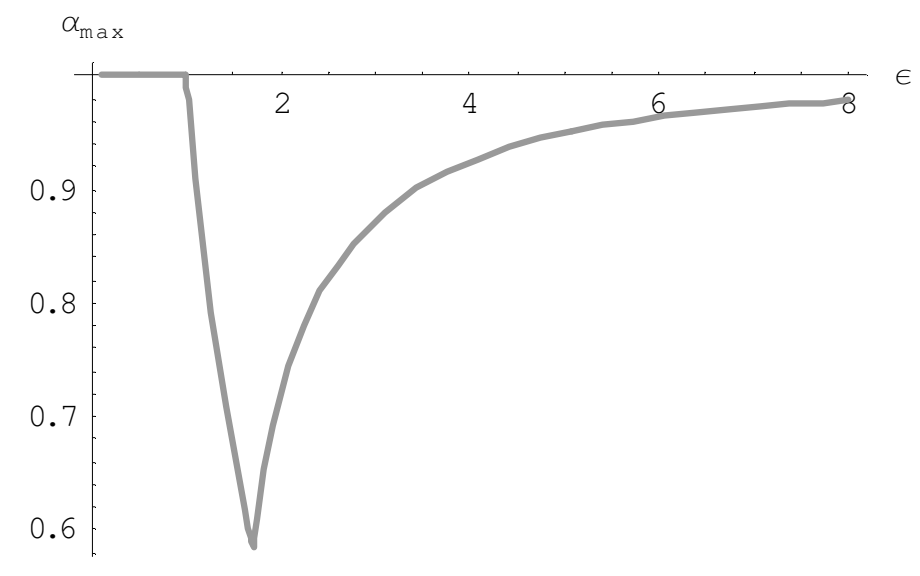

Figure 1: The non-linear relationship between pay-for-performance sensitivity $\left(\alpha_{\max }\right)$ and the (inverse of the) degree of PMC $(\varepsilon)$.

\section{Conclusion}

We examined the role of PMC in influencing the shareholders trade-off between inducing effort and fraudulent behavior and found that the pay-for-performance sensitivity is non-monotone in the strength of PMC. As a consequence, there exists a non-monotone relationship between incentives and fraudulent behavior as PMC varies: strong incentives, that is a high pay-for-performance sensitivity, together with a strong PMC may not lead to fraudulent behavior while the same incentives or even weaker one together with a weak PMC may lead to fraudulent behavior.

\section{Appendix}

Proof of Proposition 1. First order conditions for (11) are

$$
\begin{gathered}
\frac{\partial}{\partial \alpha} E(S)=\varepsilon^{2} \frac{1}{2}(1-\alpha) \eta \quad \text { for } \alpha<\frac{\gamma}{\varepsilon \Delta} \\
\frac{\partial}{\partial \alpha} E(S)=\varepsilon^{2}\left[\frac{1}{2}(1-\alpha) \eta-\frac{\Delta^{2} \gamma}{(\alpha \varepsilon \Delta+\gamma)^{2}}\right] \quad \text { for } \alpha \geq \frac{\gamma}{\varepsilon \Delta}
\end{gathered}
$$


From (12) we observe that $\alpha_{\max }=1$ if $\varepsilon<\varepsilon^{*}$. We rewrite (13) as $\frac{\partial}{\partial \alpha} E(S)=g(\alpha)-f(\alpha)$, where $g(\alpha) \equiv \frac{1}{2} \eta(1-\alpha)$ represents the marginal gains from an increase in $\alpha$ and $f(\alpha) \equiv \frac{\Delta^{2} \gamma}{(\alpha \varepsilon \Delta+\gamma)^{2}}$ represents the marginal costs of incentives owing to fraudulent behavior. Note that both $g(\alpha)$ and $f(\alpha)$ are strictly decreasing in $\alpha$, that $g(\alpha)$ is a linear function of $\alpha$ while $f(\alpha)$ is a strictly convex function of $\alpha$ and that $g(1)=0<\frac{\Delta^{2} \gamma}{(\varepsilon \Delta+\gamma)^{2}}=f(1)$, which implies that $\frac{\partial}{\partial \alpha} E(S)<0$ for $\alpha=1$. We show that under Assumption $1, g(\alpha)=f(\alpha)$ has either no solution, in which case $\frac{\partial}{\partial \alpha} E(S)<0$ for each $\alpha \in\left[\frac{\gamma}{\varepsilon \Delta}, 1\right]$, or one solution $\widehat{\alpha}$, in which case $\frac{\partial}{\partial \alpha} E(S)>0$ for each $\alpha \in\left[\frac{\gamma}{\varepsilon \Delta}, \widehat{\alpha}\right)$ and $\frac{\partial}{\partial \alpha} E(S)<0$ for each $\alpha \in(\widehat{\alpha}, 1]$.

Part (i). For $\varepsilon>\bar{\varepsilon}$ we have that $g\left(\frac{\gamma}{\varepsilon \Delta}\right)>f\left(\frac{\gamma}{\varepsilon \Delta}\right)$. Since $g(1)<f(1)$ and because of the above mentioned properties of $g(\alpha)$ and $f(\alpha)$, there exists a unique $\widehat{\alpha}$ such that $g(\widehat{\alpha})=f(\widehat{\alpha})$ where $\frac{\partial}{\partial \alpha} E(S)>0$ for each $\alpha \in\left[\frac{\gamma}{\varepsilon \Delta}, \widehat{\alpha}\right)$ and $\frac{\partial}{\partial \alpha} E(S)<0$ for each $\alpha \in(\widehat{\alpha}, 1]$. To prove that $\widehat{\alpha}$ is a unique maximum note that $\varepsilon>\bar{\varepsilon}>\varepsilon^{*}$. Consequently, for $\varepsilon>\bar{\varepsilon}, 1>\frac{\gamma}{\varepsilon \Delta}$ and thus no maximum exists with $\alpha<\frac{\gamma}{\varepsilon \Delta}$. To prove that $\frac{\partial}{\partial \varepsilon} \widehat{\alpha}>0$ and $\frac{d \widehat{\alpha}}{d \gamma}<0$ observe that, since $g(1)<f(1)$ and since a unique $\widehat{\alpha}$ solving $g(\widehat{\alpha})=f(\widehat{\alpha})$ exists, it follows that $\left|g_{\alpha}(\widehat{\alpha})\right|>\left|f_{\alpha}(\widehat{\alpha})\right|$. Moreover, since $\widehat{\alpha} \geq \frac{\gamma}{\varepsilon \Delta}$, $f_{\varepsilon}(\alpha)<0, f_{\gamma}(\alpha)>0$ and using the implicit function theorem we obtain $\frac{d \widehat{\alpha}}{d \varepsilon}=-\frac{f_{\varepsilon}(\widehat{\alpha})}{\left|f_{\alpha}(\widehat{\alpha})-g_{\alpha}(\widehat{\alpha})\right|}>0$ and $\frac{d \widehat{\alpha}}{d \varepsilon}=-\frac{f_{\gamma}(\widehat{\alpha})}{\left|f_{\alpha}(\widehat{\alpha})-g_{\alpha}(\widehat{\alpha})\right|}<0$.

Part (ii): $\varepsilon^{*} \leq \varepsilon \leq \bar{\varepsilon}$. For $\varepsilon \leq \bar{\varepsilon}$ we have that $g\left(\frac{\gamma}{\varepsilon \Delta}\right) \leq f\left(\frac{\gamma}{\varepsilon \Delta}\right)$ and therefore either 0 or 2 solutions to the equation $g(\alpha)=f(\alpha)$ exist. We exploit the fact that $g(\alpha)$ is a linear function and that $f(\alpha)$ is a convex function to find values for $\varepsilon$ such that $f(\alpha)>g(\alpha)$ for all $\alpha \in\left[\frac{\gamma}{\varepsilon \Delta}, 1\right]$ in which case no solution to $f(\alpha)=g(\alpha)$ exists. It is sufficient to show that $\left|f_{\alpha}\left(\frac{\gamma}{\varepsilon \Delta}\right)\right|<\left|g_{\alpha}\left(\frac{\gamma}{\varepsilon \Delta}\right)\right|$, which holds for each $\varepsilon<\widetilde{\varepsilon} \equiv \frac{\gamma}{\Delta} k$. Since Assumption 1 guarantees that $\widetilde{\varepsilon}>\bar{\varepsilon}>\varepsilon^{*}$, for each $\varepsilon \in\left[\varepsilon^{*}, \bar{\varepsilon}\right], \varepsilon<\widetilde{\varepsilon}$ and thus $\frac{\partial}{\partial \alpha} E(S)<0$ for each $\alpha \in\left[\frac{\gamma}{\varepsilon \Delta}, 1\right]$ and $\frac{\partial}{\partial \alpha} E(S)>0$ for each $\alpha \in\left[0, \frac{\gamma}{\varepsilon \Delta}\right]$.

Part (iii): $\varepsilon<\varepsilon^{*}$, i.e. $1<\frac{\gamma}{\varepsilon \Delta}$ and therefore from (12) the unique maximum is $\alpha_{\max }=1$ with $\lambda=0$. 


\section{References}

Aghion, P., N. Bloom, R. Blundell, R. Griffith and P. Howitt (2005). Competition and innovation: an inverted-U relationship. Quarterly Journal of Economics, 120, 701-728.

Bebchuk, L. and Bar-Gill, O., 2003. Misreporting corporate performance. Unpublished working paper. Harvard Law School.

Bergstresser, D. and T. Philippon (2006). CEO incentives and earnings management, Journal of Financial Economics, 80, 511-529.

Burns, N., and S. Kedia (2006). The Impact of Performance-Based Compensation on Misreporting. Journal of Financial Economics, 79, 35-67.

Chan, K. L.K.C. Chan, N. Jegadeesh and J. Lakonishok (2006). Earnings Quality and Stock Returns. Journal of Business, 79, 1041-1082.

Crocker, K.J. and J. Slemrod (2007). The economics of earnings manipulation and managerial compensation. Rand Journal of Economics, 38, 698-713.

Erickson, M., M. Hanlon and E. Maydew (2006). Is there a Link between Executive Equity Incentives and Accounting Fraud? Journal of Accounting Research, 44, 113-143.

Gao, P. and R.E. Shrieves (2002). Earnings Management and Executive Compensation: A Case of Overdose of Option and Underdose of Salary?, EFA 2002 Berlin Meetings Presented Paper. Available at SSRN: http://ssrn.com/abstract=302843.

Goldman, E. and S.L. Slezak (2006). An equilibrium model of incentive contracts in the presence of information manipulation. Journal of Financial Economics, 80, 603 - 626.

Jensen, M.C. (2003). Paying People to Lie: the Truth about the Budgeting Process. European Financial Management, 9, 379-406.

Jensen, M. and W. Meckling (1976). Theory of the firm: Managerial behavior, agency costs, and ownership structure. Journal of Financial Economics, 4, 305-360.

Johnson, S.A., Ryan, H.E. and Y.S. Tian (2008). Managerial Incentives and Corporate Fraud: The Sources of Incentives Matter. Forthcoming, Review of Finance.

Kedia, S. and T. Philippon (2007). The Economics of Fraudulent Accounting. Forthcoming, Review of Financial Studies.

Murphy, K.J. (1999). Executive Compensation. In Handbook of Labor Economics, Volume IIIb. Orley Ashenfelter and David Card, eds. Amsterdam: North Holland, 2485-2563.

Povel, P., R. Singh and A. Winton (2007). Booms, Busts, and Fraud. Review of Financial Studies, 20, 1219-1254.

Raith, M. (2003). Competition, Risk, and Managerial Incentives. American Economic Review, 93, $1425-1436$.

Teoh, S.H., I. Welch and T.J. Wong (1998a). Earnings management and the long-run market performance of initial public offerings. Journal of Finance, 53, 1935-1974.

Teoh, S.H., I. Welch and T.J. Wong (1998b). Earnings management and the underperformance of seasoned equity offerings. Journal of Financial Economics, 50, 63-99.

Vives, X. (2008). Innovation and competitive pressure. Journal of Industrial Economics, 56, 419-469. 